\title{
Safe and Effective Medication Use in the Emergency Department
}

Cohen V. American Society of Health-System Pharmacists, Bethesda, Maryland, 2009. Softcover, 258 pages. ISBN 978-1-58528-233-3. US $\$ 104.00$ (US $\$ 83.00$ for ASHP members).

This first edition of Safe and Effective Medication Use in the Emergency Department is the first text to examine pharmacy practice within the emergency department. It is aimed at pharmacy directors, clinical coordinators, pharmacists, emergency physicians, nurses, and administrators who are seeking to improve medication safety in the emergency department. The book underwent prepublication review by a multidisciplinary team of reviewers, primarily from the author's place of work, the Maimonides Medical Center in Brooklyn, New York.

The stated goals of the book are to "improve deployment of technology ... or show how to modify technology to achieve regulatory goals and . . . continuity", to "describe pharmacy leadership and management and introduce the PharmER pyramid model as a means to . . . achieve The Joint Commission's Medication Management Standards", and to explain "how to respond to public health emergencies and explain current issues associated with the care of specific patient populations". The book highlights evidence-based practice, where evidence is available, and offers experience or observations where no evidence exists.

The first part of the book is dedicated to reviewing the history, unique challenges, and characteristics of emergency medicine and the history of pharmacy practice within the emergency department. The author also introduces the "PharmER pyramid", a model developed by the Maimonides Medical Center to help avoid medication errors in the emergency department. The second part of the book looks at the "anatomy" of a safe medication-use system. The next portion focuses on quality measures and assuring the quality of high-risk, high-cost medications and response to medical emergencies. The final section looks at the postgraduate specialty residency and undergraduate PharmD rotations offered at Maimonides Medical Center, the role of the pharmacy technician, and the future of clinical pharmacy services in the emergency department.

An obvious strength of this reference is the absence to date of any other texts focusing on issues related to pharmacotherapy in the emergency department; as such, it is a welcome development for emergency practice. It proves to be a good reference for a new practitioner within the area and would be of assistance 
in setting up an emergency department pharmacy practice, providing the reader with many examples of resources or references in the form of figures, tables, examples, and appendices recommended or used by the Maimonides Medical Center.

The book has a few limitations. It is published in the United States, so does not use Système International (SI) units of measure to refer to reference ranges or laboratory values. Regulatory and accreditation standards applicable in the United States, as well as algorithms specific to US emergent care (e.g., rapid-sequence intubation and advanced cardiac life support), are also discussed extensively throughout the book. This text is not intended to be a comprehensive review of emergency medicine pharmacotherapy, so would not be recommended as a primary evidence-based reference with this focus. Although many issues are raised in relation to medication use within the emergency department, the author could have expanded on a few of the concepts presented, such as how the emergency department links with the rest of the hospital when it comes to the care of boarded patients, what happens when there is no pharmacist available in the emergency department, and future clinical roles of the pharmacy technician with the emergency department.

In summary, Safe and Effective Medication Use in the Emergency Department is a good basic text, referring to a broad range of issues related to emergency medicine pharmacotherapy. I would recommend for this book to undergraduate pharmacy students, residents, PharmD students, and new practitioners interested in learning more about practice within the emergency department. The first portions of this text may also be useful for health care administrators or pharmacy managers.

Dawn Dalen, BSP, ACPR, PharmD

Clinical Pharmacist Specialist - Emergency Medicine

Kelowna General Hospital

Kelowna, British Columbia

Clinical Assistant Professor

Faculty of Pharmaceutical Sciences

University of British Columbia

Vancouver, British Columbia

\begin{tabular}{lll}
\multicolumn{4}{c}{ Advertisers } & IndeX \\
\hline & Ad Page & Prescribing Information \\
\hline Hospira / Gemcitabine & 4 & - \\
\hline Pharmaceutical Partners of Canada / Website Dosing & IFC & - \\
\hline Pharmaceutical Partners of Canada / Safety Ad & OBC & - \\
\hline Sandoz / Corporate & 2 & - \\
\hline Sanofi-Aventis / Plavix & IBC & $60-63$ \\
\hline
\end{tabular}

